\title{
Systemic Ghrelin Administration Alters Serum Biomarkers of Angiogenesis in Diet-Induced Obese Mice
}

\author{
M. Khazaei and Z. Tahergorabi \\ Department of Physiology, Isfahan University of Medical Sciences, Isfahan 81743638, Iran \\ Correspondence should be addressed to M. Khazaei; khazaei@med.mui.ac.ir
}

Received 23 December 2012; Revised 2 February 2013; Accepted 3 February 2013

Academic Editor: Weihong Pan

Copyright (c) 2013 M. Khazaei and Z. Tahergorabi. This is an open access article distributed under the Creative Commons Attribution License, which permits unrestricted use, distribution, and reproduction in any medium, provided the original work is properly cited.

\begin{abstract}
Introduction. Ghrelin is a gastrointestinal endocrine peptide that was initially identified as the endogenous ligand of growth hormone secretagogue receptor; however, recently, the cardiovascular effect of this peptide has been indicated. In this study, we investigated the effect of ghrelin administration on serum biomarkers of angiogenesis including leptin, nitric oxide (NO), vascular endothelial growth factor (VEGF), and its soluble receptor (VEGF receptor 1 or sFlt-1) in control- and diet-induced obese mice. Methods. Male C57BL/6 mice were randomly divided into four groups, normal diet (ND) or control, ND + ghrelin, high-fat-diet (HFD) or obese and HFD + ghrelin ( $n=6$ /group). Obese and control groups received either HFD or ND for 15 weeks. Then, the ghrelin was injected subcutaneously $100 \mu \mathrm{g} / \mathrm{kg}$ twice daily for 10 days. At the end of experiment, blood samples were collected for blood glucose, serum insulin, VEGF, sFlt-1, NO, and leptin measurements. Results. The obese animals had higher serum NO and leptin concentrations without changes in serum VEGF and sFlt-1 levels compared to control. Administration of ghrelin significantly increased serum VEGF and decreased serum leptin and NO concentrations in HFD group. Conclusion. Since ghrelin changes serum biomarkers of angiogenesis, it seems that it gets involved during states with abnormal angiogenesis.
\end{abstract}

\section{Introduction}

Prolonged imbalance of caloric intake and energy expenditure leads to complex metabolic disorder of obesity. It is associated with most common and chronic human diseases including type 2 diabetes, heart diseases, hypertension, and cancer [1].

Angiogenesis, the formation of new blood vessels from preexisting ones, is tightly linked with adipogenesis [2] and is considered as an essential component in development and expansion of adipose tissue [3]. Since expansion of adipose tissue (increasing cell size and number) creates adipose tissue hypoxia, it can lead to stabilization of the transcription factor hypoxia inducible factorl $\alpha$ (HIF-1 $\alpha)[4,5]$ that induces an angiogenic response [6].

Ghrelin is a gastrointestinal endocrine peptide and is identified as an endogenous ligand for the growth hormone secretagogue receptor type la (GHS-R Ia) [7]; however, it also regulates food intake and is associated with obesity [8]. Ghrelin and its receptors are expressed in endothelial cells and stimulate endothelial cell proliferation, migration, and angiogenesis [9]. Recently, the impact of ghrelin on cardiovascular system has been reported [10] including a decrease of peripheral vascular resistance in consequence an increase in cardiac index and stroke volume [11], improvement of ventricular remodeling [12], protection of myocytes from apoptosis [13], decrease of cardiac injury induced by ischemia/reperfusion (I/R) injury [14], and reduction of the infarct size (L). It also improves endothelial dysfunction, reduces vasoconstrictor effect of endothelin-1, and decreases blood pressure [10].

Plasma ghrelin level is associated with body mass index (BMI). It is indicated that obese patients have reduced plasma ghrelin levels [8]. The main objective of this study was to investigate the effect of ghrelin administration on serum biomarkers of angiogenesis including leptin, nitric oxide (NO), vascular endothelial growth factor (VEGF), and its soluble receptor (VEGF receptor 1 or sFlt-1) in control and obese mice. 


\section{Materials and Methods}

2.1. Animals. Male C57BL/6 mice (5 weeks old, $n=24$ ) were purchased from Pasteur Institute (Tehran, Iran), and three or four animals were housed together in one cage in controlled environment under a light-dark cycle (lights on at 19:00 and off at 07:00). The experimental procedures followed the Guiding Principles for the Care and Use of animals and were approved by the Isfahan University of Medical sciences. All mice were randomly divided into four groups: normal diet (ND) or control, ND + ghrelin, high-fat-diet (HFD) or obese and HFD + ghrelin ( $n=6$ /group).

2.2. Diets and Ghrelin Administration. Mice were rendered obese by the HFD (Bio-Serv Research Diets, NJ, USA; Cat \#F3282) contained with 59\% from fat, $14 \%$ from protein, and $27 \%$ from carbohydrate (of total calories) starting at 5 weeks of age for 15 weeks. The ND mice were fed a standard diet (Pasteur Institute, Iran). All groups were allowed to eat food freely and had free access to water. Body weights were measured weekly. After 15 weeks, the ghrelin (Tocris Co., Bristol, UK) was administered subcutaneously $100 \mu \mathrm{g} / \mathrm{kg}$ twice daily for 10 days $[15,16]$.

2.3. Serum Measurements. Blood glucose was measured by glucometer (ACON Lab Inc San Diego, CA, USA) ELISA kits were used for determination of mice serum insulin (Mercodia, Uppsala, Sweden), VEGF and sFlt-1 (R\&D systems, Minneapolis, USA), leptin (Invitrogen, Camarillo, CA 93012) and nitrite, the main metabolite of NO (Promega Corp, USA) concentrations.

2.4. Statistical Analysis. All values are expressed as mean \pm SEM. The statistical software SPSS version 16 was used for data analysis. One-Way ANOVA was used to compare data between groups using LSD post-hoc test. $P<0.05$ was considered statistically significant.

\section{Results}

3.1. Effect of Ghrelin on Body Weight. Figure 1 illustrates that administration of ghrelin for 10 days did not significantly change body weight in obese and control mice $(P>0.05)$.

3.2. Effect of Ghrelin on Blood Glucose and Serum Insulin Levels. As shown in Figure 2, there was a significant difference in blood glucose level between obese and control groups $(P<$ 0.05). Administration of ghrelin did not significantly change blood glucose in obese and control mice $(P>0.05)$.

Serum insulin concentration in obese mice was significantly higher than that of control $(P<0.05)$. Ghrelin administration did not alter serum insulin concentration in control groups $(P>0.05)$, while significantly reduced it in obese group $(P>0.05)$ (Figure 2$)$.

3.3. Effect of Ghrelin on Serum Biomarkers of Angiogenesis. The results indicated no significant differences in serum VEGF and sFlt-1 between obese and control animals

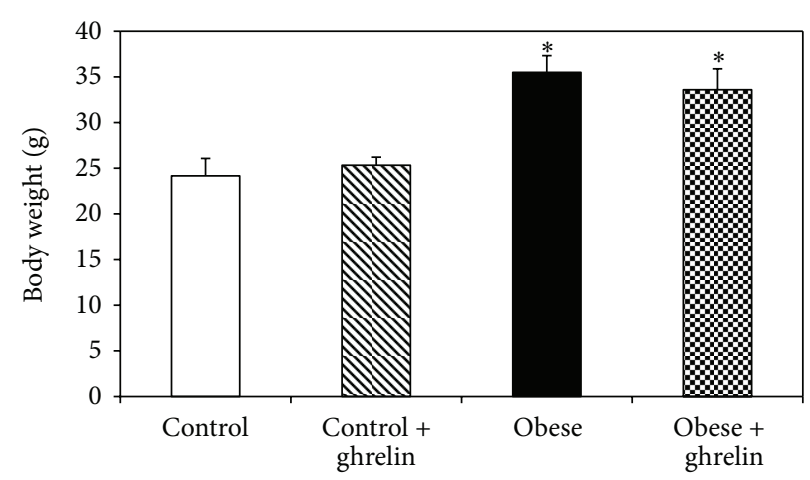

FIGURE 1: Body weight of the animals at the end of experiment. ${ }^{*} P<$ 0.05 compared to control groups.

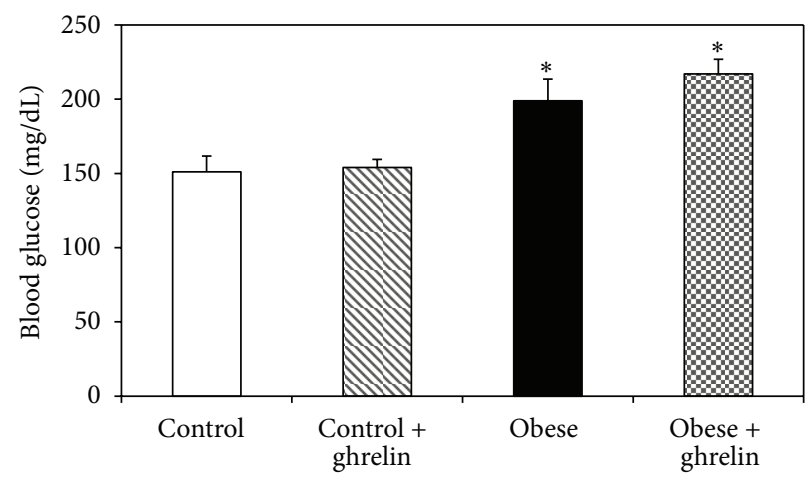

(a)

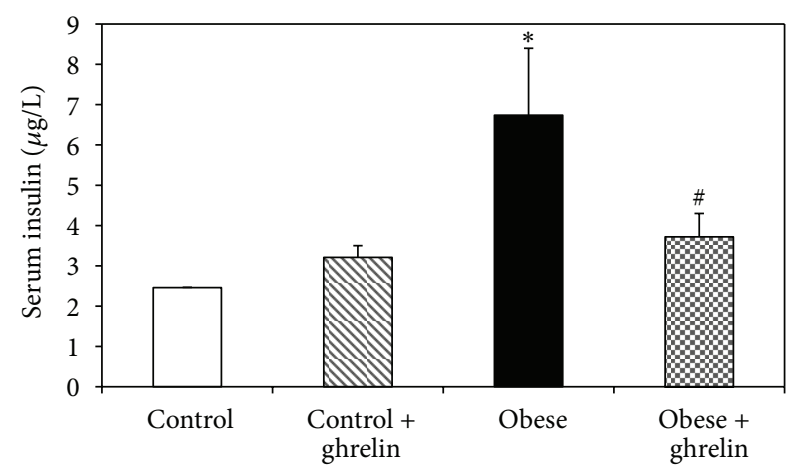

(b)

Figure 2: Blood glucose (a) and serum insulin (b) concentrations in experimental groups. ${ }^{*} P<0.05$ compared to control. ${ }^{\#} P<0.05$ compared to obese group.

$(P<0.05)$; however, serum NO concentration in obese mice was higher than that of control $(P<0.05)$. Ghrelin administration increased serum VEGF and reduced serum NO level in obese mice and had no effect on sFlt-1 concentration (Figure 3).

3.4. Serum Leptin Measurement. Serum leptin level in obese mice was higher than that of control $(P<0.05)$, and ghrelin significantly reduced it in obese group $(P<0.05)$ (Figure 4$)$. 


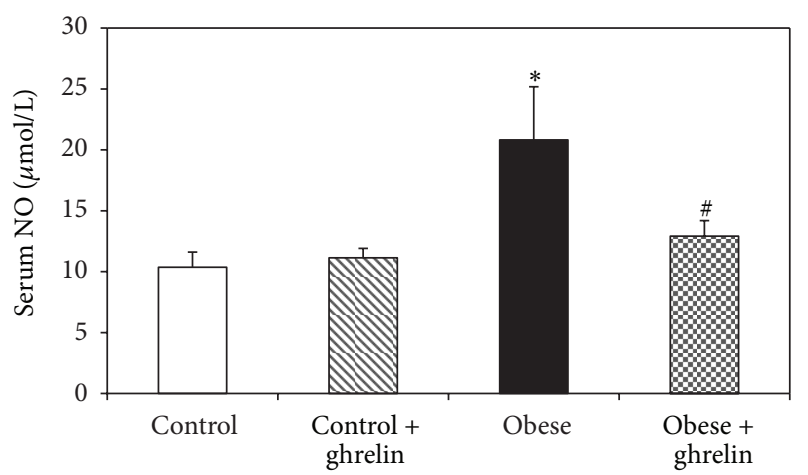

(a)

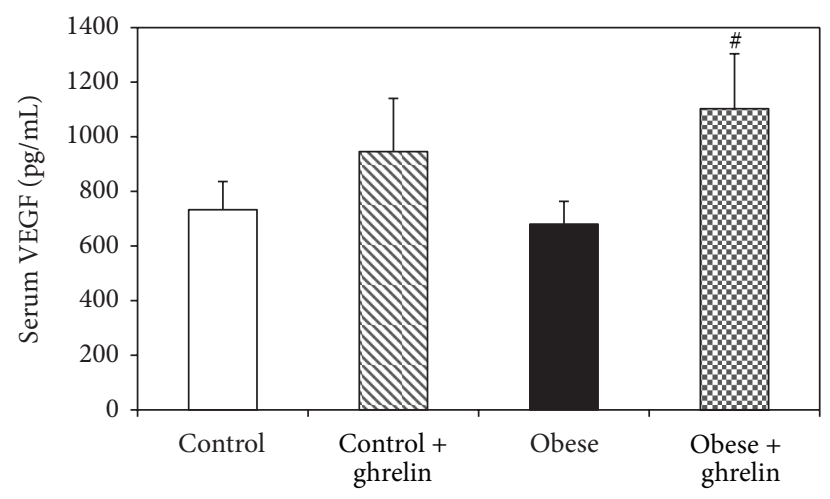

(b)

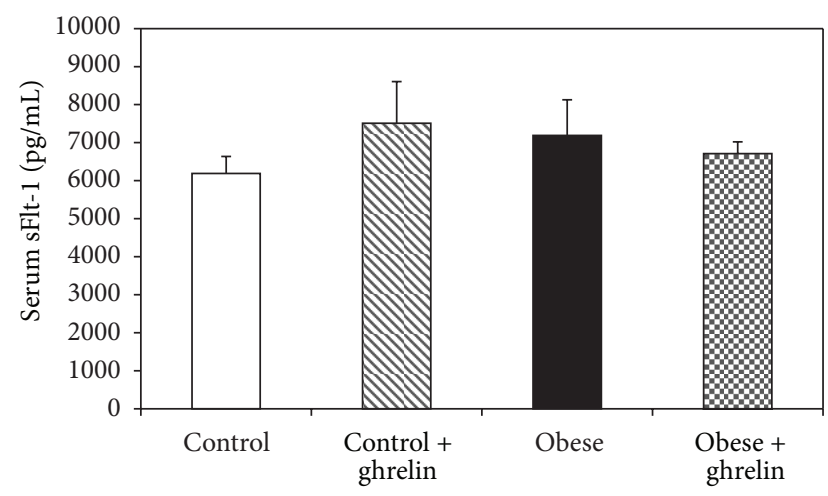

(c)

FIGURE 3: Effect of ghrelin on serum NO (a), VEGF (b), and sFlt-1 (c) concentrations. ${ }^{*} P<0.05$ compared to control. ${ }^{\#} P<0.05$ compared to obese group.

\section{Discussion}

The main finding of this study is that the obese mice had higher serum insulin, NO, and leptin concentrations compared to control without changes in serum VEGF and sFlt-1 levels. Ghrelin administration reduced serum NO, and leptin and increased serum VEGF concentrations in obese mice.

Higher blood glucose and insulin levels in HFD group indicate the insulin resistance in these animals. We demonstrated that although ghrelin treatment could not alter blood glucose level, it reduced serum insulin concentration in obese

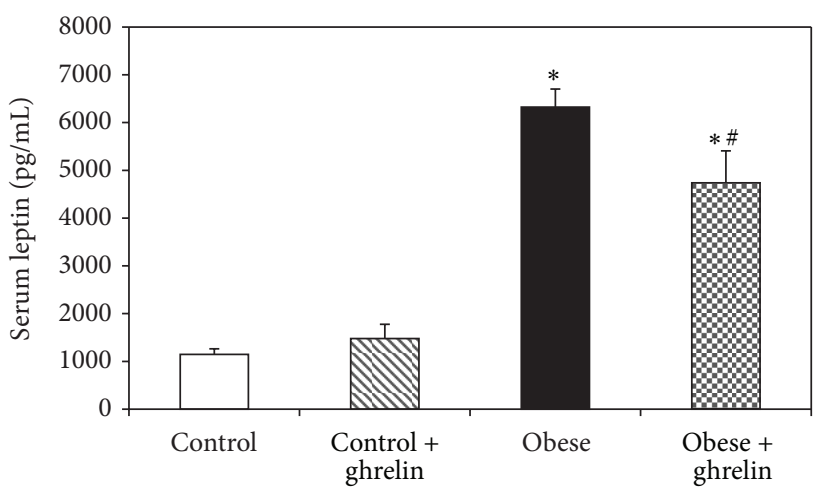

FIgURE 4: Effect of ghrelin on serum leptin level. $P<0.05$ compared to control. ${ }^{*} P<0.05$ compared to control. ${ }^{\#} P<0.05$ compared to obese group.

mice. Our data was in line with other studies [17, 18]. Ghrelin may also act on cellular glucose uptake [10] and may involve in control of glucose metabolism and insulin sensitivity [19]. Ghrelin stimulates insulin release; however, leptin inhibits insulin [20]. Perhaps, only ten days ghrelin treatment was the reason for unchanging of blood glucose level in the present study.

Modulation of vascular tissue and angiogenesis in adipose tissue is a strategy to affect obesity. Adipose tissue endothelial cells produce several angiogenic factors including leptin, NO, VEGF, FGF, HGF, and other growth factors [21]. NO is an endothelium-derived relaxing factor which has antiatherosclerotic effects through different mechanisms. However, it is a known angiogenic factor [22]. It is suggested that at the initial stage of obesity, a compensatory increase in NO production occurs due to upregulation of NO synthase [23]. On the other hand, adipogenesis increases upregulation of iNOS which increases NO synthesis due to chronic lowgrade inflammation during obesity [2]. These data are in line with the results of the present study that we showed higher serum NO concentration in obese mice.

Leptin is an adipocyte-derived hormone that not only directly promotes angiogenesis and endothelial cell migration but also upregulates VEGF expression [24]. As we expected, in the present study, the obese animals had higher serum leptin level than that of control. These data was in agreement with the previous studies [25]. We also demonstrated that HFD did not change serum VEGF and sFlt-1 concentrations. Although some studies indicated higher serum VEGF level in obese subjects [26], a recent study showed that HFD did not affect plasma concentration of VEGF [27]. VEGF binds to two tyrosine kinase receptors of sFlt-1 and VEGFR2. sFlt-1 leads to anti- or proangiogenic signaling and inhibits angiogenic signaling through sequestration of VEGF ligands [28, 29]. In the present study, HFD did not change serum concentration of sFlt-1.

In our study, ghrelin administration reduced serum $\mathrm{NO}$ and leptin and increased serum VEGF concentrations in obese mice. Ghrelin is a gastrointestinal endocrine peptide which has several impacts on cardiovascular system [10]. Ghrelin and leptin circulate in the blood and have a role in 
regulation of body weight and energy homeostasis [13]. Study in human showed that plasma ghrelin inversely correlated to degree of obesity [30] and in this study, ghrelin reduced serum leptin level in obese mice. Thus, it seems that ghrelin has a protective mechanism including leptin resistance in setting obesity. Further studies need to clarify this. An in vitro studies indicated that ghrelin activates $\mathrm{NO}$-dependent vasorelaxation in patients with metabolic syndrome [31]. Furthermore, there is a reciprocal regulation between VEGF and NO during angiogenesis process [32]. Thus, we expected that in the present study, ghrelin administration increased serum NO concentration. One explanation for this discrepancy is that ghrelin and leptin have mutually antagonistic effects on inflammatory cytokine expression in obesity [33] and reduced leptin after ghrelin administration may involve in reduction of serum NO level.

Recently, Yuan M.J. showed that in a rat model of myocardial infarction, chronic ghrelin treatment increased VEGF expression in peri-infarct zone and they suggested that ghrelin may induce angiogenesis after MI [34]. We also found that ghrelin altered serum biomarkers of angiogenesis and it seems that it may mediate angiogenesis through different mechanisms. Taken together, our results suggested that ghrelin administration changes the serum biomarkers of angiogenesis and can be involved during states with abnormal angiogenesis.

\section{Conflict of Interests}

There are no conflict of interests and the authors declare that they have no direct relationship with the mentioned commercial identities.

\section{Acknowledgment}

The authors thank the vice chancellor of Isfahan University of Medical Sciences for their support (Project no. 189142).

\section{References}

[1] F. Item and D. Konrad, "Visceral fat and metabolic inflammation: the portal theory revisited," Obesity Reviews, vol. 13, supplement 2, pp. 30-39, 2012.

[2] V. Christiaens and H. R. Lijnen, "Angiogenesis and development of adipose tissue," Molecular and Cellular Endocrinology, vol. 318, no. 1-2, pp. 2-9, 2010.

[3] L. Liu and M. Meydani, "Angiogenesis inhibitors may regulate adiposity," Nutrition Reviews, vol. 61, no. 11, pp. 384-387, 2003.

[4] J. Ye, Z. Gao, J. Yin, and Q. He, "Hypoxia is a potential risk factor for chronic inflammation and adiponectin reduction in adipose tissue of ob/ob and dietary obese mice," American Journal of Physiology, vol. 293, no. 4, pp. E1118-E1128, 2007.

[5] B. Wang, I. S. Wood, and P. Trayhurn, "Dysregulation of the expression and secretion of inflammation-related adipokines by hypoxia in human adipocytes," Pflugers Archiv European Journal of Physiology, vol. 455, no. 3, pp. 479-492, 2007.

[6] N. Halberg, T. Khan, M. E. Trujillo et al., "Hypoxia-inducible factor $1 \alpha$ induces fibrosis and insulin resistance in white adipose tissue," Molecular and Cellular Biology, vol. 29, no. 16, pp. 44674483, 2009.

[7] M. Kojima, H. Hosoda, Y. Date, M. Nakazato, H. Matsuo, and K. Kangawa, "Ghrelin is a growth-hormone-releasing acylated peptide from stomach," Nature, vol. 402, no. 6762, pp. 656-660, 1999.

[8] T. Shiiya, M. Nakazato, M. Mizuta et al., "Plasma ghrelin levels in lean and obese humans and the effect of glucose on ghrelin secretion," Journal of Clinical Endocrinology and Metabolism, vol. 87, no. 1, pp. 240-244, 2002.

[9] L. Wang, Q. Chen, G. Li, and D. Ke, "Ghrelin stimulates angiogenesis via GHSRla-dependent MEK/ERK and PI3K/Akt signal pathways in rat cardiac microvascular endothelial cells," Peptides, vol. 33, no. 1, pp. 92-100, 2012.

[10] M. Tesauro, F. Schinzari, M. Caramanti, R. Lauro, and C. Cardillo, "Cardiovascular and metabolic effects of ghrelin," Current Diabetes Reviews, vol. 6, no. 4, pp. 228-235, 2010.

[11] N. Nagaya, M. Kojima, M. Uematsu et al., "Hemodynamic and hormonal effects of human ghrelin in healthy volunteers," American Journal of Physiology, vol. 280, no. 5, pp. R1483-R1487, 2001.

[12] T. Henriques-Coelho, J. Correia-Pinto, R. Roncon-Albuquerque et al., "Endogenous production of ghrelin and beneficial effects of its exogenous administration in monocrotaline-induced pulmonary hypertension," American Journal of Physiology, vol. 287, no. 6, pp. H2885-H2890, 2004.

[13] G. Baldanzi, N. Filigheddu, S. Cutrupi et al., "Ghrelin and desacyl ghrelin inhibit cell death in cardiomyocytes and endothelial cells through ERK1/2 and PI 3-kinase/AKT," Journal of Cell Biology, vol. 159, no. 6, pp. 1029-1037, 2002.

[14] L. Chang, Y. Ren, X. Liu et al., "Protective effects of ghrelin on ischemia/reperfusion injury in the isolated rat heart," Journal of Cardiovascular Pharmacology, vol. 43, no. 2, pp. 165-170, 2004.

[15] J. P. Xu, H. X. Wang, W. Wang, L. K. Zhang, and C. S. Tang, "Ghrelin improves disturbed myocardial energy metabolism in rats with heart failure induced by isoproterenol," Journal of Peptide Science, vol. 16, no. 8, pp. 392-402, 2010.

[16] L. Li, L. K. Zhang, Y. Z. Pang et al., "Cardioprotective effects of ghrelin and des-octanoyl ghrelin on myocardial injury induced by isoproterenol in rats," Acta Pharmacologica Sinica, vol. 27, no. 5, pp. 527-535, 2006.

[17] K. Dezaki, H. Hosoda, M. Kakei et al., "Endogenous ghrelin in pancreatic islets restricts insulin release by attenuating $\mathrm{Ca}^{2+}$ signaling in $\beta$-cells: implication in the glycemic control in rodents," Diabetes, vol. 53, no. 12, pp. 3142-3151, 2004.

[18] T. Yada, K. Dezaki, H. Sone et al., "Ghrelin regulates insulin release and glycemia: physiological role and therapeutic potential," Current Diabetes Reviews, vol. 4, no. 1, pp. 18-23, 2008.

[19] J. Yang, M. S. Brown, G. Liang, N. V. Grishin, and J. L. Goldstein, "Identification of the acyltransferase that octanoylates ghrelin, an appetite-stimulating peptide hormone," Cell, vol. 132, no. 3, pp. 387-396, 2008.

[20] Y. Date, M. Nakazato, S. Hashiguchi et al., "Ghrelin is present in pancreatic $\alpha$-cells of humans and rats and stimulates insulin secretion," Diabetes, vol. 51, no. 1, pp. 124-129, 2002.

[21] Y. Cao, "Angiogenesis modulates adipogenesis and obesity," The Journal of Clinical Investigation, vol. 117, no. 9, pp. 2362-2368, 2007.

[22] J. P. Cooke, "NO and angiogenesis," Atherosclerosis Supplements, vol. 4, no. 4, pp. 53-60, 2003. 
[23] P. Codoñer-Franch, S. Tavárez-Alonso, R. Murria-Estal, J. Megías-Vericat, M. Tortajada-Girbés, and E. Alonso-Iglesias, "Nitric oxide production is increased in severely obese children and related to markers of oxidative stress and inflammation," Atherosclerosis, vol. 215, no. 2, pp. 475-480, 2011.

[24] E. Suganami, H. Takagi, H. Ohashi et al., "Leptin stimulates ischemia-induced retinal neovascularization: possible role of vascular endothelial growth factor expressed in retinal endothelial cells," Diabetes, vol. 53, no. 9, pp. 2443-2448, 2004.

[25] E. A. Hamed, M. M. Zakary, N. S. Ahmed, and R. M. Gamal, "Circulating leptin and insulin in obese patients with and without type 2 diabetes mellitus: relation to ghrelin and oxidative stress," Diabetes Research and Clinical Practice, vol. 94, no. 3, pp. 434-441, 2011.

[26] J. Gómez-Ambrosi, V. Catalán, A. Rodríguez et al., "Involvement of serum vascular endothelial growth factor family members in the development of obesity in mice and humans," Journal of Nutritional Biochemistry, vol. 21, no. 8, pp. 774-780, 2010.

[27] L. Yan, L. C. DeMars, and L. K. Johnson, "Long-term voluntary running improves diet-induced adiposity in young adult mice," Nutrition Research, vol. 32, no. 6, pp. 458-465, 2012.

[28] F. T. H. Wu, M. O. Stefanini, F. M. Gabhann, C. D. Kontos, B. H. Annex, and A. S. Popel, "A systems biology perspective on sVEGFR1: its biological function, pathogenic role and therapeutic use," Journal of Cellular and Molecular Medicine, vol. 14, no. 3, pp. 528-552, 2010.

[29] J. Tam, D. G. Duda, J. Y. Perentes, R. S. Quadri, D. Fukumura, and R. K. Jain, "Blockade of VEGFR2 and not VEGFR1 can limit diet-induced fat tissue expansion: role of local versus bone marrow-derived endothelial cells," PLoS ONE, vol. 4, no. 3, Article ID e4974, 2009.

[30] V. Tolle, M. Kadem, M. T. Bluet-Pajot et al., "Balance in Ghrelin and leptin plasma levels in anorexia nervosa patients and constitutionally thin women," Journal of Clinical Endocrinology and Metabolism, vol. 88, no. 1, pp. 109-116, 2003.

[31] M. Tesauro, F. Schinzari, M. Iantorno et al., "Ghrelin improves endothelial function in patients with metabolic syndrome," Circulation, vol. 112, no. 19, pp. 2986-2992, 2005.

[32] H. Kimura and H. Esumi, "Reciprocal regulation between nitric oxide and vascular endothelial growth factor in angiogenesis," Acta Biochimica Polonica, vol. 50, no. 1, pp. 49-59, 2003.

[33] V. D. Dixit, E. M. Schaffer, R. S. Pyle et al., "Ghrelin inhibits leptin- and activation-induced proinflammatory cytokine expression by human monocytes and T cells," The Journal of Clinical Investigation, vol. 114, no. 1, pp. 57-66, 2004.

[34] M. J. Yuan, H. He, H. Y. Hu, Q. Li, J. Hong, and C. X. Huang, "Myocardial angiogenesis after chronic ghrelin treatment in a rat myocardial infarction model," Regulatory Peptides, vol. 179, no. 1-3, pp. 39-42, 2012. 

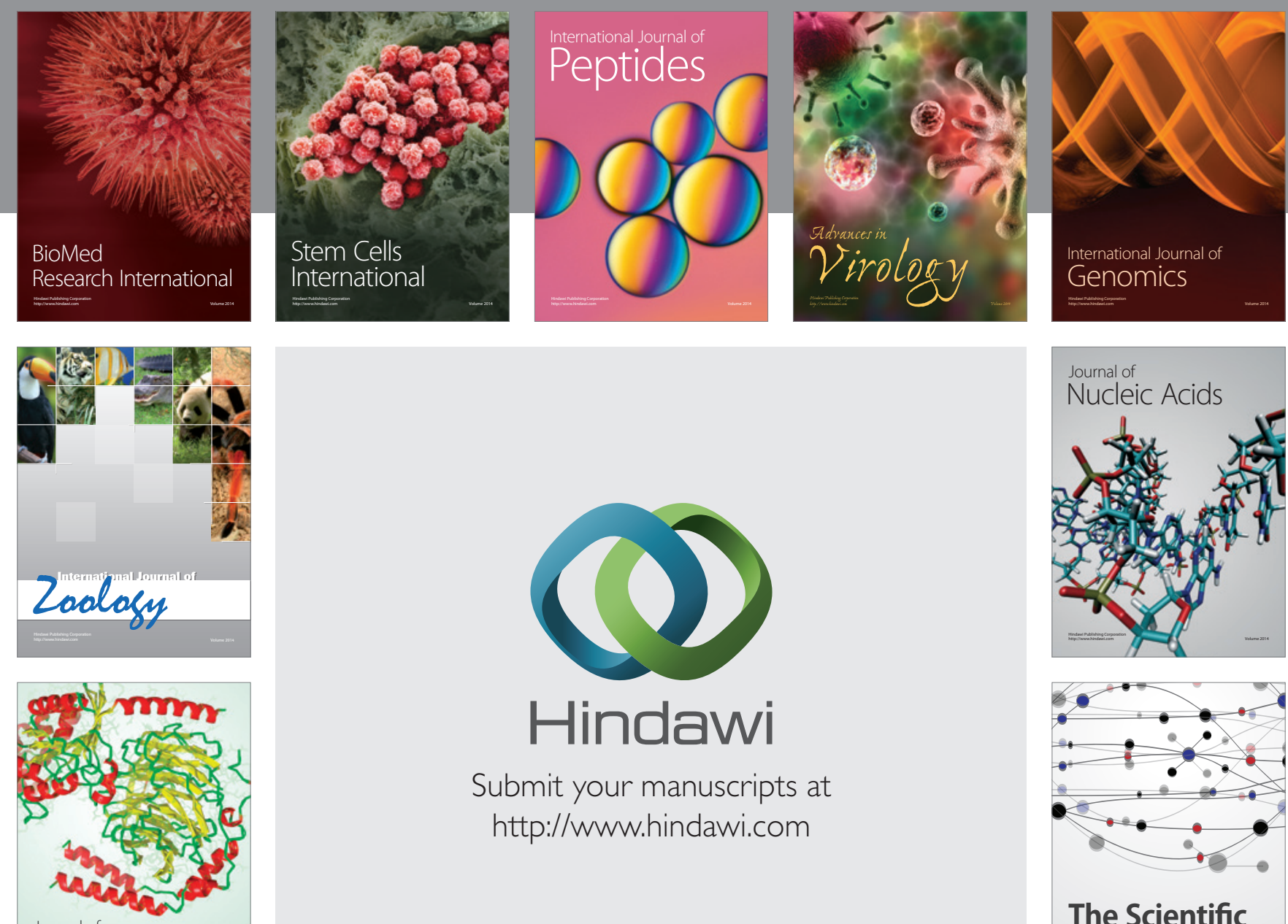

Submit your manuscripts at

http://www.hindawi.com

Journal of
Signal Transduction
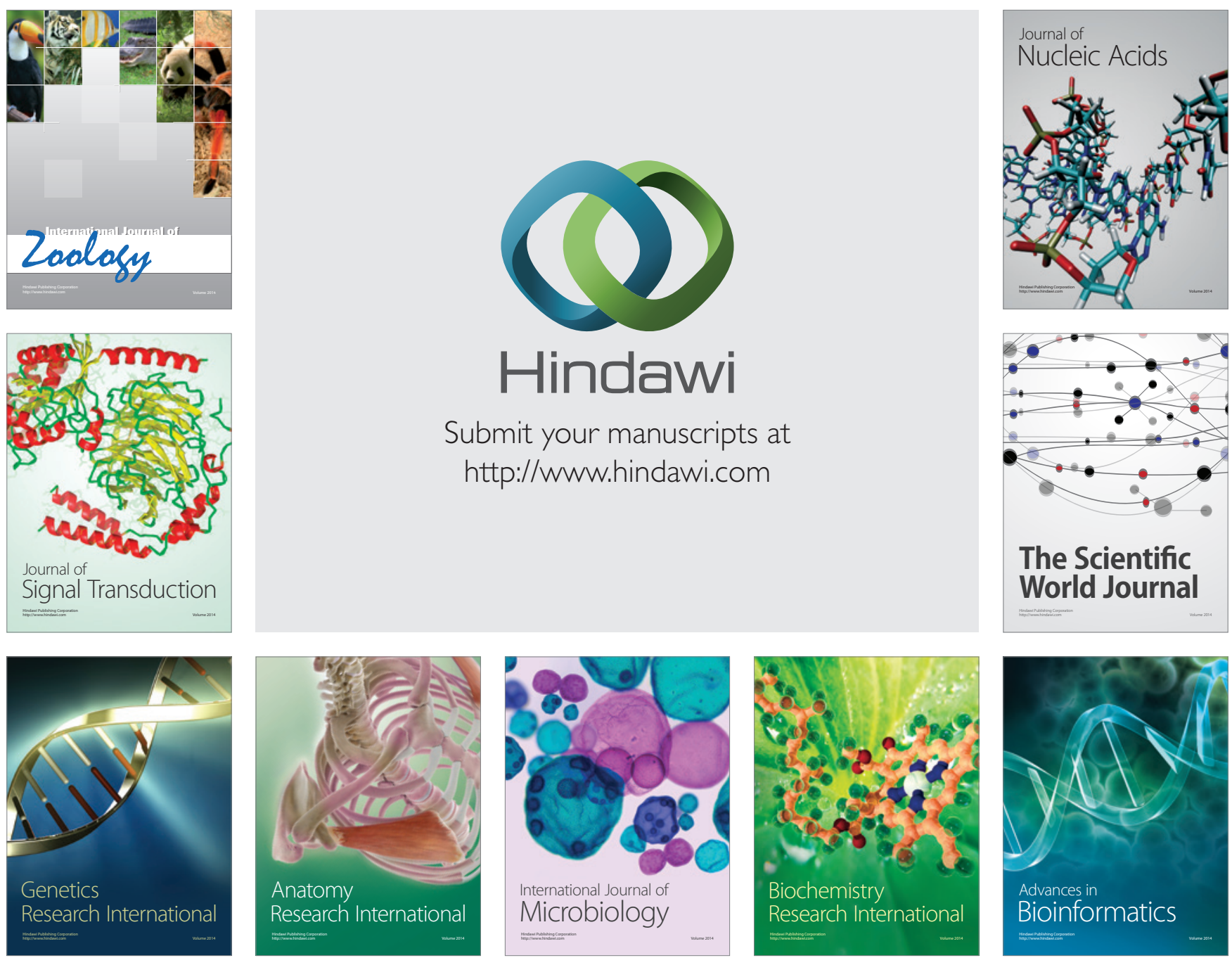

The Scientific World Journal
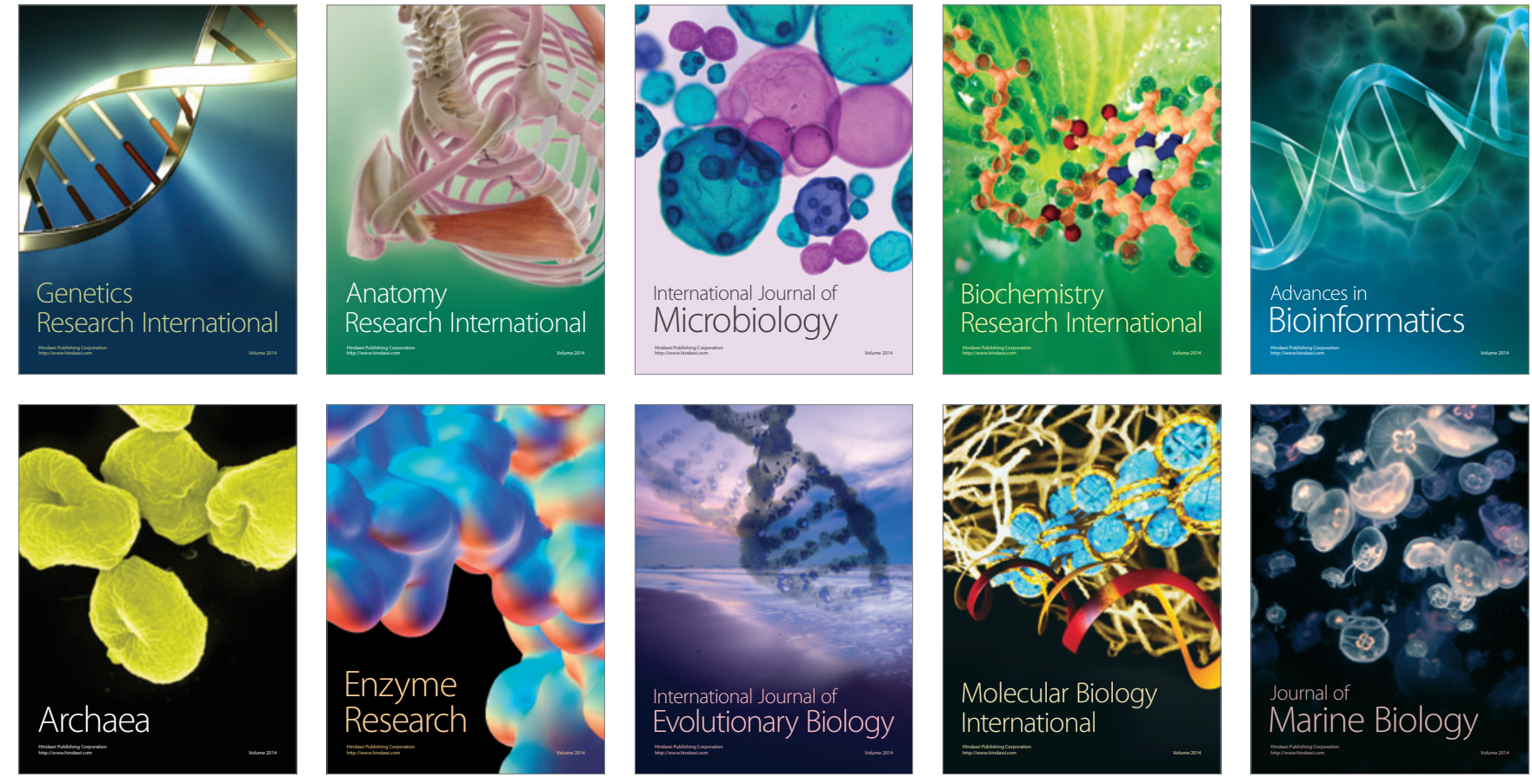